\title{
Chemical diversity in leaf and stem essential oils of Origanum vulgare L. and their effects on microbicidal activities
}

\author{
Merajuddin Khan ${ }^{1 *}$ (D), Shams T. Khan², Mujeeb Khan ${ }^{1}$, Ahmad A. Mousa ${ }^{1}$, Adeem Mahmood \\ and Hamad Z. Alkhathlan ${ }^{\text {* }}$
}

\begin{abstract}
Essential oils (EOs) from the stems and leaves of Origanum vulgare L. grown in Saudi Arabia and Jordan were analyzed by gas chromatography-mass spectrometry (GC-MS) and GC-flame ionization detector (FID) techniques on two different columns (polar and nonpolar). A detailed phytochemical analysis led to the identification of 153 constituents of these essential oils. Both Saudi and Jordanian plants are classified by chemotypes rich in cymyl-compounds. However, the Saudi Origanum contains carvacrol as the major component and is, thus, characterized as a carvacrol chemotype, while the Jordanian Origanum contains thymol as the major component, and, thus, it is classified as a thymol chemotype. In addition, the antimicrobial activities of the studied EOs and their major components, including carvacrol and thymol, were evaluated against various Gram-positive and Gram-negative microorganisms. All the tested compounds exhibited significant antimicrobial activity against all the tested bacteria. Among them, thymol demonstrated superior activity against all the tested organisms, followed by carvacrol. Moreover, results on oil composition and oil yield of $O$. vulgare L. from different parts of the world is compared in detail with the present outcomes.
\end{abstract}

Keywords: Essential oils, NMR, GC-MS, Origanum vulgare L., Lamiaceae

\section{Introduction}

Recently, the demand for the development of natural products from medicinal and aromatic plants as substitutes for artificial additives and as pharmacologically active agents has increased significantly (Atanasov et al. 2015). Among the different natural products, essential oils (EOs) have gained immense popularity in various industries, including the food, cosmetics, and pharmaceutical industries, because of their remarkable characteristics such as, strong odor, unique colors, and high volatility (Carvalho et al. 2016; Maggio et al. 2016). In particular, EOs play a significant role in the health care sector by virtue of their remarkable biological activities, which are directly associated with their biologically active essential oil components (Raut and Karuppayil 2014).

\footnotetext{
*Correspondence: mkhan3@ksu.edu.sa; khathlan@ksu.edu.sa

1 Department of Chemistry, College of Science, King Saud University, P.O.

Box 2455, Riyadh 11451, Saudi Arabia

Full list of author information is available at the end of the article
}

EOs are oily substances produced by different parts of the plants, including flowers, buds, leaves, twigs, stems, seeds, and fruits (Bakkali et al. 2008). Generally, these oils are comprised of complex mixtures of volatile substances that are biosynthesized by plants. These substances can be broadly classified into several groups, such as aromatic and aliphatic compounds, terpenes, and terpenoids (Pichersky et al. 2006).

Most of the biological activities of EOs, particularly their antimicrobial activity, is associated with oxygenated terpenes, such as alcohols and phenolic terpenes. However, a few hydrocarbons have been found to exhibit significant antibacterial effects (Bassolé and Juliani 2012). Usually, the complex interactions between the diverse classes of phytoconstituents, such as phenols, alcohols, aldehydes, ketones, or other hydrocarbons of EOs are responsible for their antibacterial activities. In some cases, these interactions may lead to antagonistic or synergistic effects that contribute to the antibacterial activity of EOs, and even minor components of EOs can play 
a critical role in these effects (Gutierrez et al. 2008). It has been widely reported that EOs containing phenols or aldehydes, including thymol, eugenol, carvacrol, and cinnamaldehyde, as major components display higher antimicrobial activities than EOs containing terpenes or alcohols (Ait-Ouazzou et al. 2011; Sacchetti et al. 2005).

For instance, various species of Thymus and Origanum display excellent antimicrobial activities because of the presence of phenolic phytoconstituents including thymol and carvacrol (de Barros et al. 2009; Khan et al. 2018; Soković et al. 2009). In contrast, the high antibacterial activities of Ocimum basilicum, Syzygium aromaticum, and Eugenia caryophillus are attributed to eugenol (Vlase et al. 2014). Indeed, the EO of Origanum has been extensively studied because of its diverse contents and remarkable characteristics (Lukas et al. 2015). Origanum is an economically important genus belonging to the Lamiaceae family. Many genera, such as thyme (Thymus), sage (Salvia), lavender (Lavandula), basil (Ocimum), and mint (Mentha), of the Lamiaceae family are well known for their commercial values and their applications in ethnobotanical practices (Ibadullayeva et al. 2012). Within this family, Origanum is included in the subfamily Nepetoideae of tribe Mentheae and subtribe Menthinae and comprises about 40 species, which are naturally distributed in different parts of the world including the Mediterranean, Central Asia, the Arabian Peninsula, Northern Africa, and Europe (De Martino et al. 2009).

The Origanum genus is extensively found in the Mediterranean region, particularly concentrated in the eastern Mediterranean region (Aligiannis et al. 2001). These Origanum species are typically applied as flavoring agents for food but are also used as additives in some beverages (Janssen et al. 1987; Valnet et al. 1978). Origanum species are generally identified by the presence of a range of secondary metabolites and by the differences in the characteristic phytoconstituents of their essential oils. In particular, the EOs of Origanum species show great variation in their chemical diversity for various reasons, including ecological and environmental effects, as well as genetic variations (Vokou et al. 1993). In addition, other factors, including available nutrients (nitrogen, water, and minerals), photoperiod, radiation, and temperature also have a significant effect on the content and quality of the EOs of O. vulgare L. (Kokkini et al. 1994). Therefore, a comparative investigation of the EOs of O. vulgare L. from different regions would be useful to explore the chemical diversity of this species and to realize its industrial potential. Although extensive studies of the EOs of Origanum species have been conducted, however, $O$. vulgare L. populations from the Middle East have been poorly explored. Moreover, in majority of preveous studies, only the characterization of the oil composition of whole plant is described and determination of chemical components of different organs of $O$. vulgare $\mathrm{L}$. and their comparison is very rare. Thus, in this study, we analyzed the phytochemical compounds of volatile oils extracted from the leaves and stems of $O$. vulgare L. grown in two Middle Eastern countries: Saudi Arabia and Jordan (Scheme 1). The chemical profiling of the EOs was performed by different characterization techniques including NMR, gas chromatography (GC)-flame ionization detector (FID), and GC-mass spectrometry (MS) techniques on two different (polar and non-polar) columns. Furthermore, the antimicrobial properties of EOs and their main compounds obtained from the plants of two different regions were also determined against Gram-negative and Grampositive bacterial strains.

\section{Materials and methods \\ Plant material}

Whole plants of O. vulgare L. grown on the outskirts of Amman city in the north-central region of Jordan and in Al-Kharj, Saudi Arabia were procured in February and March of 2013, respectively. Verification of the plant materials was carried out by Dr. Jacob Thomas Pandalayil, a plant taxonomist at KSU, Riyadh. Representative samples of the plant species of Jordanian (OVHZK-303 J) and Saudi (OVHZK-303) O. vulgare L. are maintained in our research group laboratory.

\section{Isolation of volatile oils from the leaf and stem of $O$. vulgare $\mathrm{L}$.}

First, the leaves and stems of freshly harvested whole plants of $O$. vulgare L. were separated and cut into small pieces. The resultant pieces of the leaves and stems of $O$. vulgare L. grown in Jordan and Saudi Arabia were separately processed for hydro-distillation in a Clevenger apparatus for $3 \mathrm{~h}$ according to a previously reported method (Khan et al. 2018), yielding light-yellow oils. The yields of the oils from the leaves and stems of Saudi $O$. vulgare $\mathrm{L}$. were $1.3 \%$ and $0.4 \%(\mathrm{w} / \mathrm{w})$ on a fresh weight basis, respectively. The oil yields from the leaves and stems of Jordanian $O$. vulgare $\mathrm{L}$. were $0.6 \%$ and $0.2 \%$ $(\mathrm{w} / \mathrm{w})$ on a fresh weight basis, respectively. The volatile oils attained after the hydro-distillation were dried using anhydrous $\mathrm{Na}_{2} \mathrm{SO}_{4}$ as the dehydrating agent and stored at $4{ }^{\circ} \mathrm{C}$ until further use.

\section{Chemicals}

For the dilution of the essential oils, high purity diethyl ether bought from Sigma-Aldrich, Germany, was used. Pure essential oil components, e.g., carvacrol, $\gamma$-terpinene, $\alpha$-pinene, thymol, and $\beta$-pinene, along with some essential oil fractions enriched with volatile components, such as camphene, $\beta$-caryophyllene, caryophyllene 

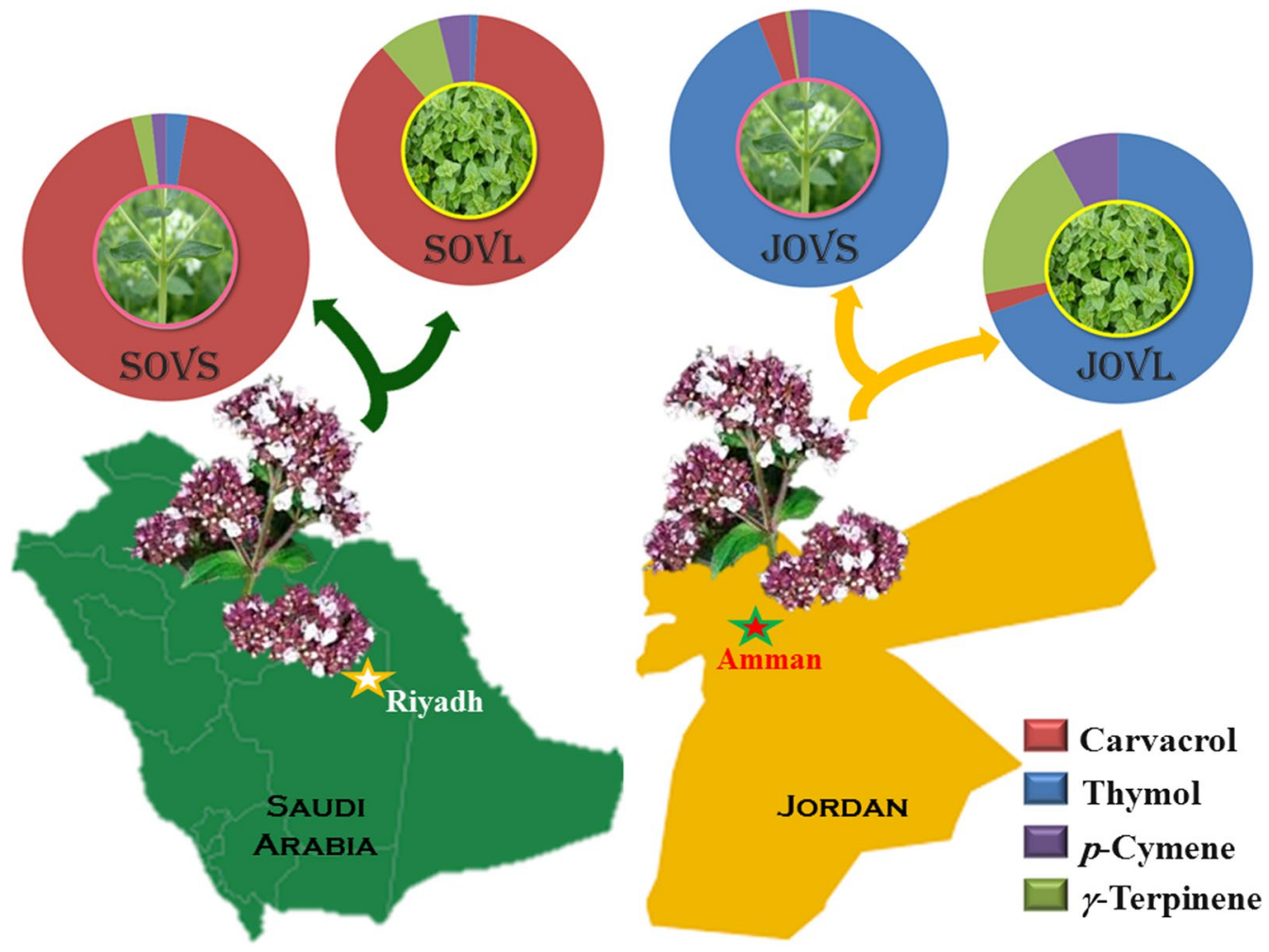

Scheme 1 Composition of dominant components in the essential oils of Saudi and Jordanian O. vulgare L.

oxide, cis-3-hexen-1-ol, p-cymene, terpinene-4-ol, 1-octen-3-ol, $\alpha$-terpinene, and 3-octanone, were available in our laboratory and were used for co-injection/comparative analysis.

\section{GC and GC-MS analysis of $O$. vulgare L. essential oils}

The essential oils obtained through hydro-distillation of the leaves and stems of $O$. vulgare L. collected from Saudi Arabia and Jordan were analyzed on HP-5MS and DBWax columns using previously described methods (Khan et al. 2016). The identified constituents and the contents of the leaf and stem essential oils of Jordanian and Saudi O. vulgare L. are documented in Table 1 according to the elution order of each compounds on the HP-5MS column.

\section{Retention indices}

The linear retention indices (LRIs) of the leaf and stem essential oil compounds of Jordanian and Saudi O. vulgare L. were determined following a reported method (Khan et al. 2016), and these are listed in Table 1.

\section{Identification of volatile components}

Identification of the volatile components was carried out via analysis on both columns (DB-Wax and HP-5MS) in a similar fashion to that reported previously (Khan et al. 2016). GC-FID Chromatogram with identified peaks of oil components on HP-5MS column is shown in Figs. 1, 2, Additional file 1: Figs. S1, S2.

\section{Nuclear magnetic resonance (NMR) analysis}

The ${ }^{1} \mathrm{H}$ and ${ }^{13} \mathrm{C}$ NMR spectra of the pure compounds were done in similar fashion as described earlier (Khan et al. 2018). Details are given in supporting information (Additional file 1).

\section{Bacterial strains and growth medium}

Four bacterial strains, Escherichia coli ATCC 25922, Pseudomonas aeruginosa ATCC 75853, Micrococcus luteus ATCC 10240, and Staphylococcus aureus ATCC 92213 were used as representative Gram-positive and Gram-negative bacteria. E. coli, P. aeruginosa, M. luteus, and $S$. aureus were grown on autoclaved Luria broth, nutrient broth, Müller-Hinton broth, and nutrient broth, respectively, at their respective optimal growth temperatures. For long-term preservation, strains were maintained on agar plates of their respective media and were stored at $-80{ }^{\circ} \mathrm{C}$ in $20 \%$ glycerol. 
Table 1 Chemical constituents of leaf and stem volatile oils of O. vulgare L. grown in Saudi Arabia and Jordan

\begin{tabular}{|c|c|c|c|c|c|c|c|c|c|}
\hline No. & Compound* & LRI $_{\text {Lit }}$ & LRI $_{\text {Exp }}^{a}$ & LRI $\left.\right|_{\text {Exp }} ^{p}$ & SOVS (\%) & SOVL (\%) & JOVS $(\%)^{b}$ & JOVL (\%) & Identification ${ }^{c}$ \\
\hline 1 & trans-2-Hexenal & 846 & 852 & 1217 & $\mathrm{t}$ & - & - & $\mathrm{t}$ & 1,2 \\
\hline 2 & cis-3-Hexen-1-ol & 850 & 854 & 1389 & $\mathrm{t}$ & $\mathrm{t}$ & - & $\mathrm{t}$ & $1,2,3$ \\
\hline 3 & trans-2-Hexen-1-ol & 854 & 857 & 1412 & - & - & - & $\mathrm{t}$ & 1,2 \\
\hline 4 & cis-2-hexen-1-ol & 859 & 865 & - & $t$ & - & - & $\mathrm{t}$ & 1,2 \\
\hline 5 & 1-Hexanol & 863 & 867 & 1358 & - & - & - & $\mathrm{t}$ & 1,2 \\
\hline 6 & 2-Heptanol & 894 & 897 & - & $\mathrm{t}$ & $\mathrm{t}$ & - & - & 1,2 \\
\hline 7 & Tricyclene & 921 & 922 & 1010 & - & $\mathrm{t}$ & - & $\mathrm{t}$ & 1,2 \\
\hline 8 & a-Thujene & 924 & 927 & 1023 & $0.2 \pm 0.00$ & $1.4 \pm 0.06$ & $t$ & $1.0 \pm 0.51$ & $1,2,3$ \\
\hline 9 & a-Pinene & 932 & 934 & 1018 & 0.1 & 0.6 & $\mathrm{t}$ & 0.5 & $1,2,3$ \\
\hline 10 & $a$-Fenchene & 945 & 945 & - & - & $\mathrm{t}$ & - & - & 1,2 \\
\hline 11 & Camphene & 946 & 949 & 1060 & $\mathrm{t}$ & 0.1 & 0.1 & 0.1 & $1,2,3$ \\
\hline 12 & Benzaldehyde & 952 & 961 & 1523 & $t$ & $\mathrm{t}$ & - & $\mathrm{t}$ & 1,2 \\
\hline 13 & Sabinene & 969 & 974 & 1118 & 0.1 & 0.6 & - & 0.1 & $1,2,3$ \\
\hline 14 & $\beta$-Pinene & 974 & 977 & 1104 & $\mathrm{t}$ & 0.3 & - & 0.1 & $1,2,3$ \\
\hline 15 & 1-Octen-3-ol & 974 & 979 & 1455 & 0.2 & 0.4 & 0.8 & 1.2 & $1,2,3$ \\
\hline 16 & 3-Octanone & 979 & 987 & 1255 & $t$ & $\mathrm{t}$ & 0.1 & 0.1 & $1,2,3$ \\
\hline 17 & 6-Methyl-5-hepten-2-one ${ }^{d}$ & 981 & - & 1339 & - & - & - & $\mathrm{t}$ & 1,2 \\
\hline 18 & $\beta$-Myrcene & 988 & 992 & 1163 & $0.4 \pm 0.05$ & $2.0 \pm 0.07$ & $0.1 \pm 0.00$ & $1.9 \pm 0.14$ & $1,2,3$ \\
\hline 19 & 3-Octanol & 988 & 996 & 1399 & 0.3 & 0.4 & 1.3 & 2.0 & $1,2,3$ \\
\hline 20 & a-Phellandrene & 1002 & 1005 & - & 0.1 & 0.2 & - & 0.3 & 1,2 \\
\hline 21 & 8-3-Carene & 1008 & 1011 & 1146 & $\mathrm{t}$ & 0.1 & - & 0.1 & 1,2 \\
\hline 22 & a-Terpinene & 1014 & 1017 & 1177 & $0.4 \pm 0.00$ & $1.4 \pm 0.00$ & $0.1 \pm 0.00$ & $2.7 \pm 0.07$ & $1,2,3$ \\
\hline 23 & m-Cymene & - & 1023 & - & - & $\mathrm{t}$ & - & - & 1,2 \\
\hline 24 & p-Cymene & 1020 & 1025 & 1269 & $1.4 \pm 0.07$ & $3.2 \pm 0.00$ & $1.6 \pm 0.07$ & $6.8 \pm 0.00$ & $1,2,3$ \\
\hline 25 & Limonene $^{d}$ & 1024 & - & 1196 & 0.1 & 0.3 & - & 0.4 & 1,2 \\
\hline 26 & $\beta$-Phellandrene & 1025 & 1030 & 1205 & 0.2 & 0.5 & 0.1 & 0.5 & 1,2 \\
\hline 27 & 1,8-Cineole & 1026 & 1033 & 1208 & $t$ & $\mathrm{t}$ & - & $\mathrm{t}$ & 1,2 \\
\hline 28 & cis- $\beta$-Ocimene & 1032 & 1039 & 1235 & $t$ & 0.1 & - & 0.2 & 1,2 \\
\hline 29 & Benzeneacetaldehyde & 1036 & 1045 & 1635 & $\mathrm{t}$ & $\mathrm{t}$ & - & $\mathrm{t}$ & 1,2 \\
\hline 30 & trans- $\beta$-Ocimene & 1044 & 1049 & 1252 & $\mathrm{t}$ & 0.1 & - & 0.1 & 1,2 \\
\hline 31 & $\gamma$-Terpinene & 1054 & 1060 & 1245 & $1.9 \pm 0.06$ & $6.2 \pm 0.07$ & $0.4 \pm 0.00$ & $17.0 \pm 0.14$ & $1,2,3$ \\
\hline 32 & cis-Sabinene hydrate & 1065 & 1068 & 1471 & 0.6 & 0.9 & 0.3 & 0.3 & 1,2 \\
\hline 33 & cis-Linalool oxide $^{d}$ & 1067 & - & 1048 & - & - & - & $\mathrm{t}$ & 1,2 \\
\hline 34 & trans-Linalool oxide & 1084 & 1087 & - & $\mathrm{t}$ & - & - & - & 1,2 \\
\hline 35 & $a$-Terpinolene & 1086 & 1090 & 1282 & 0.1 & 0.1 & - & 0.1 & $1,2,3$ \\
\hline 36 & p-Cymenene ${ }^{d}$ & 1089 & - & 1438 & - & - & - & $\mathrm{t}$ & 1,2 \\
\hline 37 & Linalool $^{d}$ & 1095 & - & 1552 & 0.1 & 0.2 & 0.6 & $\mathrm{t}$ & $1,2,3$ \\
\hline 38 & trans-Sabinene hydrate & 1098 & 1099 & 1556 & $2.6 \pm 0.08$ & $3.5 \pm 0.07$ & - & $0.5 \pm 0.03$ & $1,2,3$ \\
\hline 39 & Nonanal & 1100 & 1104 & 1394 & - & - & - & $\mathrm{t}$ & 1,2 \\
\hline 40 & p-Mentha-1 (7), 8-diene ${ }^{d}$ & 1003 & - & 1167 & - & - & - & $\mathrm{t}$ & 1,2 \\
\hline 41 & 1-Octen-3-yl acetate & 1110 & 1113 & - & $\mathrm{t}$ & - & - & - & 1,2 \\
\hline 42 & 1,3,8-p-Menthatriene & 1108 & 1113 & - & - & $\mathrm{t}$ & - & - & 1,2 \\
\hline 43 & cis-p-Menth-2-en-1-ol & 1118 & 1123 & - & 0.1 & 0.1 & 0.1 & $\mathrm{t}$ & 1,2 \\
\hline 44 & a-Campholenal & 1122 & 1128 & 1491 & $\mathrm{t}$ & $\mathrm{t}$ & - & - & 1,2 \\
\hline 45 & allo-Ocimene & 1128 & 1130 & 1373 & - & $\mathrm{t}$ & - & $\mathrm{t}$ & 1,2 \\
\hline 46 & cis-p-Mentha-2,8-dien-1-ol & 1133 & 1138 & - & - & $\mathrm{t}$ & - & - & 1,2 \\
\hline 47 & trans-Pinocarveol & 1135 & 1142 & - & 0.1 & $\mathrm{t}$ & $\mathrm{t}$ & - & 1,2 \\
\hline 48 & trans-Verbenol & 1140 & 1148 & 1685 & $\mathrm{t}$ & $\mathrm{t}$ & 0.1 & - & 1,2 \\
\hline 49 & Isoborneol & 1155 & 1159 & - & - & $\mathrm{t}$ & - & - & 1,2 \\
\hline
\end{tabular}


Table 1 (continued)

\begin{tabular}{|c|c|c|c|c|c|c|c|c|c|}
\hline No. & Compound* & LRI $_{\text {Lit }}$ & $L R I_{\text {Exp }}^{a}$ & LRI & SOVS (\%) & SOVL $(\%)^{b}$ & JOVS (\%) & JOVL $(\%)^{b}$ & Identification $^{c}$ \\
\hline 50 & Borneol & 1165 & 1168 & 1708 & 0.7 & 0.1 & 1.4 & 0.2 & 1,2 \\
\hline 51 & Umbellulone & 1167 & 1175 & 1646 & $t$ & $\mathrm{t}$ & - & - & 1,2 \\
\hline 52 & Terpinen-4-ol & 1174 & 1180 & 1608 & $1.6 \pm 0.06$ & $0.9 \pm 0.07$ & $0.8 \pm 0.00$ & $0.5 \pm 0.21$ & $1,2,3$ \\
\hline 53 & m-Cymen-8-ol & 1176 & 1184 & - & $\mathrm{t}$ & - & - & - & 1,2 \\
\hline 54 & p-Cymen-8-ol & 1179 & 1188 & 1854 & $\mathrm{t}$ & $\mathrm{t}$ & 0.2 & $\mathrm{t}$ & 1,2 \\
\hline 55 & $a$-Terpineol & 1186 & 1193 & 1703 & 0.1 & 0.1 & 0.2 & $\mathrm{t}$ & 1,2 \\
\hline 56 & Myrtenal & 1195 & 1196 & - & 0.2 & 0.1 & - & - & 1,2 \\
\hline 57 & cis-Dihydro carvone & 1191 & 1199 & 1611 & 0.1 & 0.2 & 0.1 & 0.1 & 1,2 \\
\hline 58 & cis-Piperitol $^{d}$ & 1195 & - & 1753 & $t$ & $\mathrm{t}$ & - & - & 1,2 \\
\hline 59 & trans-Dihydro carvone & 1200 & 1203 & 1631 & 0.1 & - & - & $t$ & 1,2 \\
\hline 60 & n-Decanal & 1201 & 1207 & 1495 & $\mathrm{t}$ & 0.1 & - & - & 1,2 \\
\hline 61 & Verbenone & 1204 & 1212 & - & 0.1 & - & - & - & 1,2 \\
\hline 62 & Linalool formate $^{d}$ & 1214 & - & 1577 & - & $\mathrm{t}$ & - & - & 1,2 \\
\hline 63 & trans-Carveol & 1215 & 1215 & 1842 & $\mathrm{t}$ & $\mathrm{t}$ & - & $\mathrm{t}$ & 1,2 \\
\hline 64 & cis-Carveol & 1226 & 1229 & - & $\mathrm{t}$ & $\mathrm{t}$ & 0.1 & - & 1,2 \\
\hline 65 & Methyl thymol & 1232 & 1233 & - & $t$ & $\mathrm{t}$ & - & - & 1,2 \\
\hline 66 & Isobornyl formate & 1235 & 1235 & 1584 & - & $\mathrm{t}$ & - & $\mathrm{t}$ & 1,2 \\
\hline 67 & (E)-Ocimenone & 1235 & 1238 & - & - & $\mathrm{t}$ & - & - & 1,2 \\
\hline 68 & Methyl carvacrol & 1241 & 1246 & - & 0.1 & $\mathrm{t}$ & - & - & 1,2 \\
\hline 69 & Carvotanacetone & 1244 & 1249 & 1683 & $\mathrm{t}$ & $\mathrm{t}$ & - & - & 1,2 \\
\hline 70 & Geraniol & 1249 & 1253 & - & - & - & 0.1 & - & 1,2 \\
\hline 71 & Linalool acetate & 1254 & 1256 & - & 0.1 & - & 0.1 & - & 1,2 \\
\hline 72 & Thymoquinone & 1248 & 1259 & - & - & 0.1 & & $\mathrm{t}$ & 1,2 \\
\hline 73 & cis-Chrysanthenyl acetate & 1261 & 1262 & - & $\mathrm{t}$ & - & 0.1 & - & 1,2 \\
\hline 74 & (2E)-Decenal & - & 1266 & - & - & $\mathrm{t}$ & - & - & 1,2 \\
\hline 75 & Perilla aldehyde & 1269 & 1281 & - & $\mathrm{t}$ & - & - & - & 1,2 \\
\hline 76 & Bornyl acetate & 1284 & 1287 & 1585 & $\mathrm{t}$ & $\mathrm{t}$ & - & $\mathrm{t}$ & 1,2 \\
\hline 77 & Thymol & 1289 & 1294 & 2190 & $2.1 \pm 0.00$ & $0.8 \pm 0.07$ & $68.73 \pm 4.50$ & $59.1 \pm 0.28$ & $1,2,3,4$ \\
\hline 78 & Carvacrol & 1298 & 1311 & 2222 & $79.5 \pm 0.77$ & $72.8 \pm 0.21$ & $2.4 \pm 0.14$ & $2.0 \pm 0.07$ & $1,2,3,4$ \\
\hline 79 & (2E,4E)-Decadienal & 1315 & 1319 & - & $\mathrm{t}$ & 0.1 & - & - & 1,2 \\
\hline 80 & Myrtenyl acetate & 1324 & 1328 & - & $\mathrm{t}$ & - & - & - & 1,2 \\
\hline 81 & trans-Carvyl acetate & 1339 & 1333 & & - & $\mathrm{t}$ & - & - & 1,2 \\
\hline 82 & $\delta$-Elemene & 1335 & 1343 & - & 0.1 & 0.1 & - & - & 1,2 \\
\hline 83 & Thymol acetate & 1349 & 1357 & 1870 & $t$ & $\mathrm{t}$ & - & $\mathrm{t}$ & 1,2 \\
\hline 84 & Eugenol & 1356 & 1361 & 2162 & 0.1 & $\mathrm{t}$ & 0.1 & $\mathrm{t}$ & 1,2 \\
\hline 85 & Carvacrol acetate & 1370 & 1376 & 1876 & 0.2 & 0.1 & - & $t$ & 1,2 \\
\hline 86 & a-Copaene & 1374 & 1382 & - & - & $\mathrm{t}$ & & - & 1,2 \\
\hline 87 & $\beta$-Bourbonene & 1387 & 1391 & - & - & $\mathrm{t}$ & $t$ & - & 1,2 \\
\hline 88 & $\beta$-Elemene & 1389 & 1397 & - & $t$ & $\mathrm{t}$ & - & $t$ & 1,2 \\
\hline 89 & n-Tetradecane & 1400 & 1400 & - & $t$ & $\mathrm{t}$ & - & - & $1,2,3$ \\
\hline 90 & Methyl eugenol & 1403 & 1406 & - & $t$ & - & - & - & 1,2 \\
\hline 91 & cis-a-Bergamotene & 1411 & 1419 & 1570 & $t$ & $\mathrm{t}$ & $\mathrm{t}$ & - & 1,2 \\
\hline 92 & $\beta$-Caryophyllene & 1417 & 1427 & 1600 & $1.5 \pm 0.00$ & $1.2 \pm 0.00$ & $2.5 \pm 0.14$ & $0.9 \pm 0.00$ & $1,2,3$ \\
\hline 93 & $\beta$-Copaene & 1430 & 1436 & - & $t$ & $\mathrm{t}$ & - & - & 1,2 \\
\hline 94 & trans- $\alpha$-Bergamotene & 1432 & 1440 & 1588 & 0.1 & $\mathrm{t}$ & 0.1 & $\mathrm{t}$ & 1,2 \\
\hline 95 & $a$-Guaiene & 1437 & 1446 & 1592 & $\mathrm{t}$ & $\mathrm{t}$ & - & - & 1,2 \\
\hline 96 & Seychellene & 1444 & 1453 & - & - & $\mathrm{t}$ & - & - & 1,2 \\
\hline 97 & a-Humulene & 1452 & 1461 & 1672 & 0.1 & 0.1 & 0.1 & $\mathrm{t}$ & 1,2 \\
\hline 98 & cis-Muurola-4(14),5-diene & 1465 & 1470 & - & $\mathrm{t}$ & $\mathrm{t}$ & - & - & 1,2 \\
\hline
\end{tabular}


Table 1 (continued)

\begin{tabular}{|c|c|c|c|c|c|c|c|c|c|}
\hline No. & Compound* & LRI $_{\text {Lit }}$ & LRI $\left.\right|_{\text {Exp }} ^{a}$ & LRIPxp & SOVS (\%) & SOVL (\%) & JOVS (\%) & JOVL $(\%)^{b}$ & Identification $^{c}$ \\
\hline 99 & y-Muurolene & 1478 & 1483 & 1692 & $\mathrm{t}$ & $t$ & - & - & 1,2 \\
\hline 100 & Germacrene-D & 1484 & 1488 & 1712 & 0.2 & 0.2 & 0.1 & $t$ & $1,2,3$ \\
\hline 101 & n-Pentadecane & 1500 & 1500 & - & $\mathrm{t}$ & $\mathrm{t}$ & - & - & $1,2,3$ \\
\hline 102 & Bicyclogermacrene & 1500 & 1504 & 1737 & 0.3 & 0.2 & - & - & $1,2,3$ \\
\hline 103 & $(E, E)$-a-Farnesene & 1505 & 1510 & - & $t$ & $t$ & - & - & 1,2 \\
\hline 104 & $\beta$-Bisabolene & 1505 & 1513 & 1729 & 0.1 & $t$ & 0.3 & 0.1 & 1,2 \\
\hline 105 & $\beta$-lonol & 1412 & 1517 & 1915 & $t$ & $t$ & - & - & 1,2 \\
\hline 106 & $\gamma$-Cadinene & 1513 & 1521 & 1763 & $t$ & $t$ & - & $\mathrm{t}$ & 1,2 \\
\hline 107 & trans-Calamenene & 1521 & 1529 & 1835 & $t$ & $t$ & $t$ & $\mathrm{t}$ & 1,2 \\
\hline 108 & a-Cadinene & 1537 & 1533 & 1777 & t & - & - & - & 1,2 \\
\hline 109 & cis-Nerolidol & 1531 & 1547 & 2017 & $\mathrm{t}$ & $\mathrm{t}$ & - & - & 1,2 \\
\hline 110 & Thymohydro quinone & 1553 & 1555 & - & - & $\mathrm{t}$ & - & $\mathrm{t}$ & 1,2 \\
\hline 111 & trans-Nerolidol & 1561 & 1566 & 2046 & $t$ & - & & 0.1 & 1,2 \\
\hline 112 & Germacrene-D-4-ol & 1574 & 1576 & 2057 & $t$ & $t$ & - & - & 1,2 \\
\hline 113 & Spathulenol & 1577 & 1585 & 2132 & 0.1 & $t$ & - & - & $1,2,3$ \\
\hline 114 & Caryophyllene oxide & 1582 & 1592 & 1991 & 0.1 & $t$ & 0.3 & 0.1 & $1,2,3$ \\
\hline 115 & Viridiflorol & 1592 & 1600 & - & $t$ & $t$ & - & - & 1,2 \\
\hline 116 & Cedrol & 1600 & 1610 & - & - & - & - & $t$ & 1,2 \\
\hline 117 & Humulene epoxide II & 1608 & 1614 & - & t & - & - & - & 1,2 \\
\hline 118 & 1,10-di-epi-Cubenol & 1618 & 1623 & 2065 & $t$ & $t$ & - & - & 1,2 \\
\hline 119 & a-Muurolol & 1644 & 1646 & - & - & $t$ & - & $\mathrm{t}$ & 1,2 \\
\hline 120 & T-Cadinol & 1638 & 1648 & 2179 & 0.1 & - & - & - & 1,2 \\
\hline 121 & $\beta$-Eudesmol & 1649 & 1659 & - & - & - & - & $\mathrm{t}$ & 1,2 \\
\hline 122 & $a$-Cadinol & 1652 & 1662 & 2237 & t & $t$ & $0 . t$ & - & 1,2 \\
\hline 123 & $\beta$-Bisabolol & 1674 & 1675 & - & 0.1 & $\mathrm{t}$ & 0.2 & - & 1,2 \\
\hline 124 & 1-Tetradecanol & 1671 & 1678 & - & - & $t$ & - & - & 1,2 \\
\hline 125 & a-Bisabolol & 1685 & 1689 & - & - & - & $\mathrm{t}$ & - & 1,2 \\
\hline 126 & n-Heptadecane & 1700 & 1700 & 1700 & $t$ & $t$ & - & - & $1,2,3$ \\
\hline 127 & Pentadecanal & - & 1715 & - & 0.1 & $\mathrm{t}$ & $\mathrm{t}$ & - & 1,2 \\
\hline 128 & $(E, E)$-Farnesol & 1742 & 1746 & - & - & - & $\mathrm{t}$ & - & 1,2 \\
\hline 129 & Tetradecanoic acid & - & 1767 & 2693 & - & - & 0.1 & & 1,2 \\
\hline 130 & 14-Hydroxy-a-muurolene & 1779 & 1780 & - & $t$ & - & - & - & 1,2 \\
\hline 131 & Eudesm-7(11)-en-4-ol, acetate & 1839 & 1846 & - & $t$ & - & $t$ & - & 1,2 \\
\hline 132 & Pentadecanoic acid & - & 1871 & - & $t$ & $t$ & $\mathrm{t}$ & - & 1,2 \\
\hline 133 & cis-Spiroether & 1879 & 1889 & - & $t$ & - & - & - & 1,2 \\
\hline 134 & trans-Spiroether & 1890 & 1896 & - & $t$ & $t$ & - & - & 1,2 \\
\hline 135 & 2-Heptadecanone & - & 1908 & - & $t$ & $t$ & - & - & 1,2 \\
\hline 136 & Methyl hexadecanoate & 1921 & 1926 & 2208 & $\mathrm{t}$ & - & - & - & 1,2 \\
\hline 137 & Palmitic acid & 1959 & 1959 & & t & - & 0.3 & - & 1,2 \\
\hline 138 & $n$-Hexadecyl acetate & 2003 & 2005 & 2301 & 0.1 & $\mathrm{t}$ & 0.2 & - & 1,2 \\
\hline 139 & $(E, E)$-Geranyl linalool & 2026 & 2033 & 2541 & 0.7 & $t$ & 0.9 & - & 1,2 \\
\hline 140 & Manool & 2056 & 2068 & 2668 & $t$ & - & 0.1 & - & 1,2 \\
\hline 141 & $\begin{array}{l}\text { 3,3,4,5,5,8-hexamethyl-2,6-dihydro-s- } \\
\text { indacene-1,7-dione }\end{array}$ & - & 2083 & 2437 & $0.3 \pm 0.00$ & $0.1 \pm 0.00$ & $1.5 \pm 0.00$ & - & 1,2 \\
\hline 142 & Phytol & 1942 & 2105 & 2622 & - & - & 0.1 & - & 1,2 \\
\hline 143 & 2-tert-Butyl-4-(dimethylbenzyl)phenol & - & 2125 & 2612 & $0.1 \pm 0.05$ & $t$ & $2.1 \pm 0.00$ & - & 1,2 \\
\hline 144 & Linoleic acid & 2132 & 2141 & - & 0.2 & $\mathrm{t}$ & 1.2 & - & 1,2 \\
\hline 145 & Methyl octadecanoate & 2124 & 2149 & - & - & - & 0.1 & - & 1,2 \\
\hline 146 & Octadecanoic acid & - & 2179 & - & - & - & 0.1 & - & 1,2 \\
\hline 147 & cis-13-Octadecen-1-yl acetate & - & 2193 & - & $t$ & - & 0.1 & - & 1,2 \\
\hline
\end{tabular}


Table 1 (continued)

\begin{tabular}{llllllllll}
\hline No. & Compound $^{*}$ & LRI $_{\text {Lit }}$ & LRI $_{\text {Exp }}^{\mathbf{a}}$ & LRI Exp $_{\text {Ex }}^{\mathbf{p}}$ & SOVS (\%) $^{\mathbf{b}}$ & SOVL (\%) $^{\mathbf{b}}$ & JOVS (\%) $^{\mathbf{b}}$ & JOVL (\%) $^{\mathbf{b}}$ & Identification $^{\mathbf{c}}$ \\
\hline 148 & $n$-Docosane & 2200 & 2200 & 2200 & 0.1 & $\mathrm{t}$ & 0.2 & - & $1,2,3$ \\
149 & $n$-Tricosane & 2300 & 2300 & 2300 & $\mathrm{t}$ & - & 0.9 & - & $1,2,3$ \\
150 & trans-Totarol & 2314 & 2320 & - & $\mathrm{t}$ & - & - & - & 1,2 \\
151 & 3a-Acetoxy manool & 2359 & 2378 & - & $\mathrm{t}$ & - & 0.2 & - & 1,2 \\
152 & $n$-Pentacosane & 2500 & 2500 & 2500 & $\mathrm{t}$ & - & 0.1 & - & $1,2,3$ \\
153 & $n$-Hexacosane & 2600 & 2600 & 2600 & - & - & $\mathrm{t}$ & - & $1,2,3$ \\
Total identified & & & & 98.4 & 99.0 & 91.8 & 99.2 & \\
\hline
\end{tabular}

* Components are listed in their order of elution from HP-5 MS column; ${ }^{\mathrm{b}}=$ Mean percentage calculated from flame ionization detector (FID) data and compounds higher than $1.0 \%$ are highlighted in italicface and their $\pm S D(n=2)$ are mentioned; $\left.L R\right|_{L i t}$ linear retention index from the literature (Adams 2007); $L R I_{\text {Exp }}^{a}$, determined linear retention index against mixture of $n$-alkanes (C8-C31) on HP-5 MS column; LRIIXxp, determined linear retention index against mixture of $n$-alkanes (C8-C31) on DB-wax column; SOVS, stem volatile oils of Saudi O. vulgare L.; SOVL, leaves volatile oil of Saudi O. vulgare L.; JOVS stem volatile oils of Jordanian O. vulgare L.; JOVL leaves volatile oil of Jordanian $O$. vulgare L.; Identification by; 1, linear retention index (LRI) identical to literatures (cf. exp. part); 2 , comparison of mass spectra (MS) with the library entries of mass spectra databases (cf. exp. part); 3 , co-injection/comparison with the LRI and mass spectra of standards; 4 , ${ }^{1} \mathrm{H}$ and ${ }^{13} \mathrm{C} \mathrm{NMR} \mathrm{spectra;} \mathrm{t}$, trace $(<0.05 \%)$; didentified from DB-Wax column

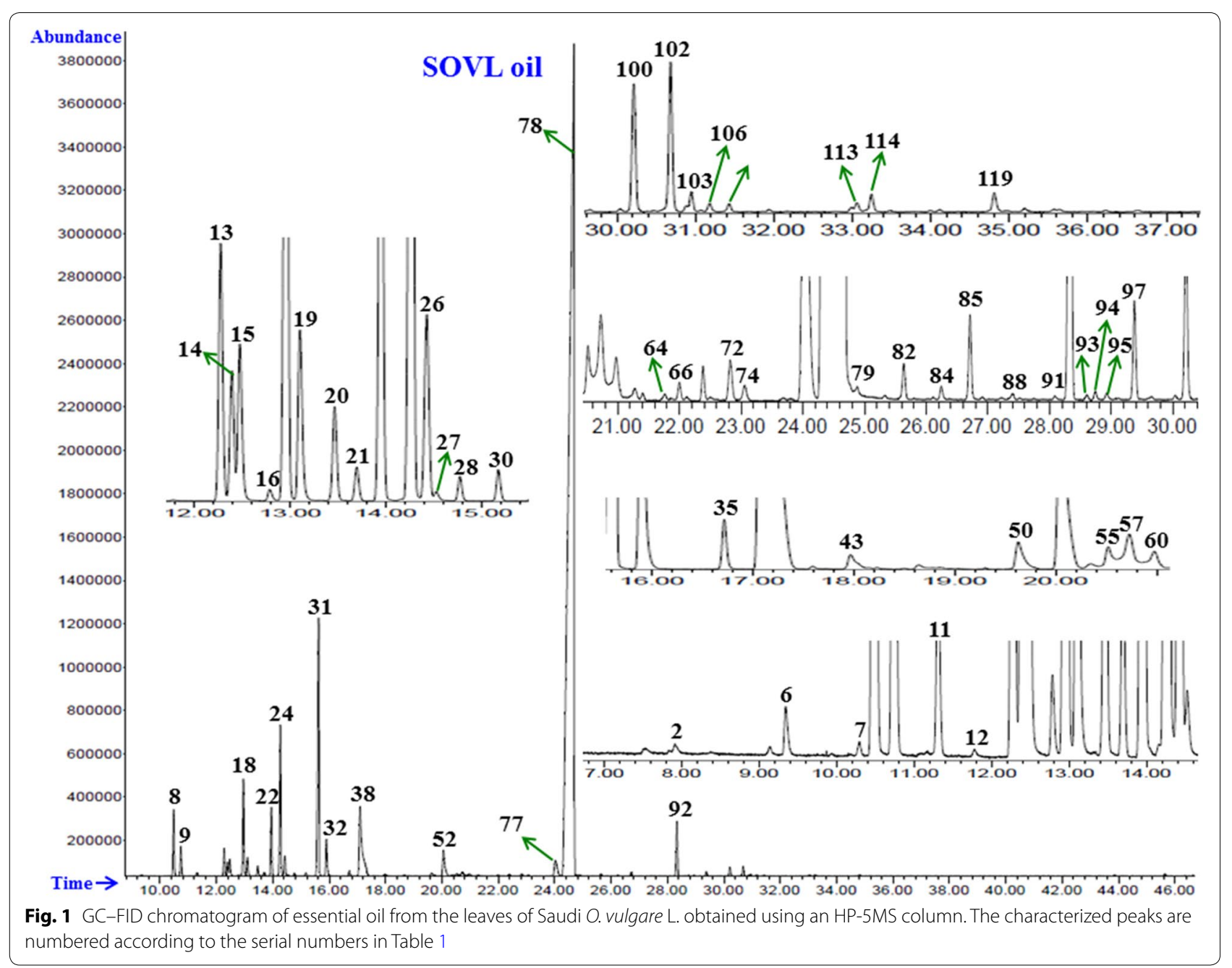




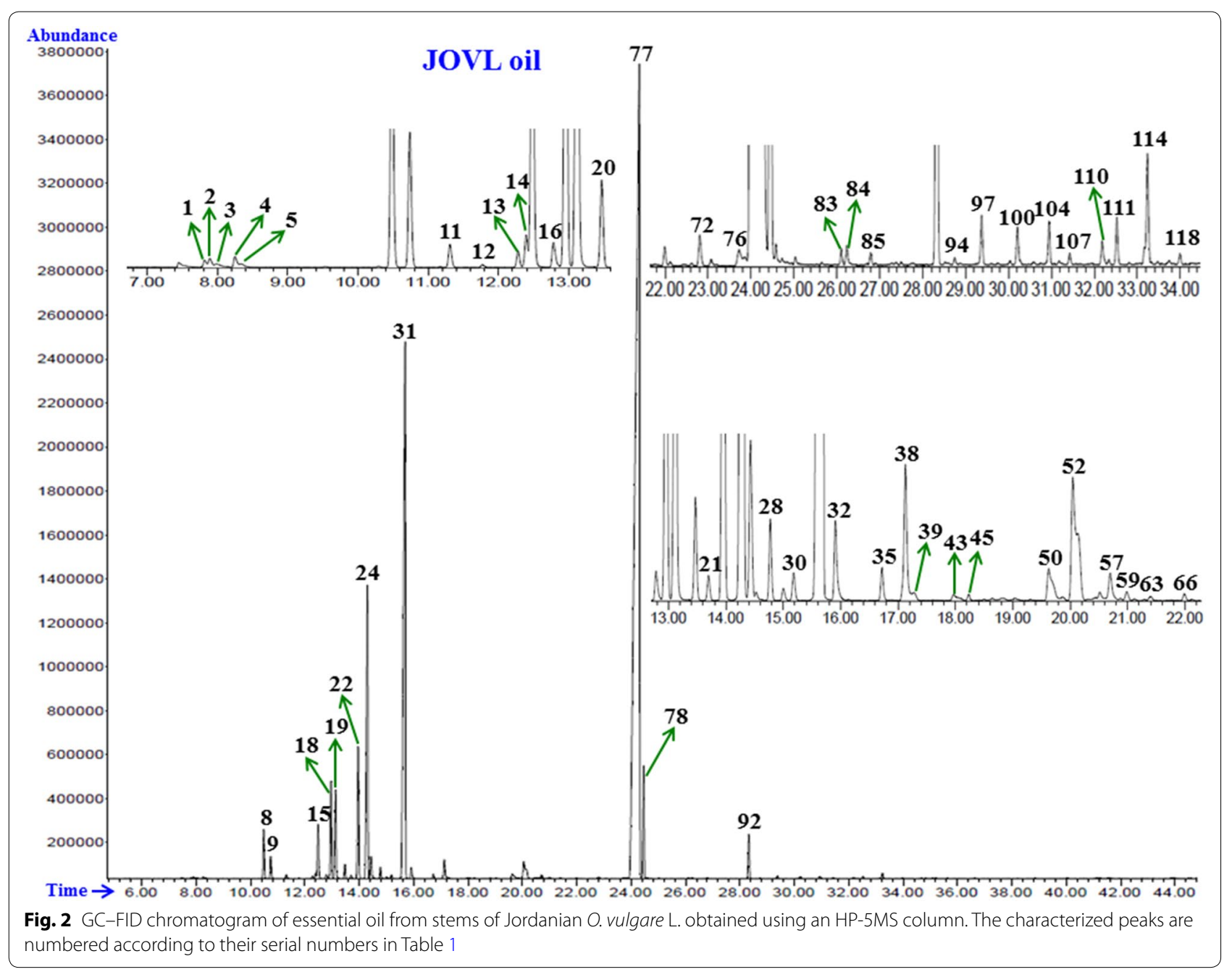

\section{Evaluation of antimicrobial activity}

For determining the antimicrobial activity of the test compounds, microdilution assays in 96-well plates were used. Cells of E. coli, P. aeruginosa, M. luteus, and $S$. aureus were grown in their respective broths until the logarithmic growth phase. An aliquot of $10 \mu \mathrm{L}$ from each culture was added to each well of a 96-well plate containing $90 \mu \mathrm{L}$ of fresh culture medium. Test compounds prepared in dimethyl sulfoxide (DMSO) were added to the wells in triplicate to final concentrations of 50, 100, 200, 300, 400, and $500 \mu \mathrm{g} / \mathrm{mL}$. Ampicillin (Amp) and kanamycin $(\mathrm{Km})$ were added to final concentrations of 10 , $20,30,40$, and $50 \mu \mathrm{g} / \mathrm{mL}$ to the culture media as positive controls. The plates were incubated on a rotary shaker at $37^{\circ} \mathrm{C}$ and $140 \mathrm{rpm}$ for $8 \mathrm{~h}$. The optical absorbance at $600 \mathrm{~nm}$ (OD600) was measured using an enzyme-linked immunosorbent assay reader (Multiskan Ascent, Labsystems, Helsinki, Finland) at hourly intervals. The OD600 at a given time was subtracted from the OD600 at $0 \mathrm{~h}$ to record the change in the OD of each sample. The results presented are the mean \pm standard error of three independent experiments. $P$ values were calculated using an unpaired Student's $t$-test in GraphPad (GraphPad Software, Inc., La Jolla, CA, USA). The p values considered significant for different tests are mentioned in the figure captions. $\mathrm{MIC}$ and $\mathrm{IC}_{50}$ values were calculated using the standard protocols and have been described elsewhere (Khan et al. 2017; Veiga et al. 2019).

\section{Results}

The hydro-distillation of the leaves and stems of O.vulgare L. from both Saudi Arabia and Jordan was performed in a Clevenger-type apparatus, which yielded light-yellow oils. Based on the fresh weight of the materials, the EOs of the leaves and stems of Saudi O. vulgare L. were obtained in yields of $1.30 \%$ and $0.40 \% \mathrm{w} / \mathrm{w}$; in contrast, the EOs of the same parts of its Jordanian counterpart were found to be $0.60 \%$ and $0.24 \% \mathrm{w} / \mathrm{w}$ from 
the leaves and stems, respectively. Notably, the studied parts of both Saudi and Jordanian O. vulgare L. produced a good oil yield, ranging from 0.2 to $1.3 \%$, when compared to their counterparts found in different parts of the world, as shown in Additional file 1: Table S1. Apart from the Origanum species found in Turkey and Tunisia, which produce an excellent oil yield in the range of 4-7\%, most species found in other parts of the world produce oil yields of $<1 \%$ (Additional file 1: Table S1).

A detailed phytochemical analysis of the essential oils led to the identification of a total of 153 compounds from these oils (EOs from the leaves and stems of $O$. vulgare L. from Saudi Arabia and Jordan). The analysis was performed via GC-MS and GC-FID using both polar and nonpolar columns. Among these constituents, $28 \mathrm{com}-$ pounds were found to be common in the EOs of the leaves and stems of $O$. vulgare $\mathrm{L}$. from both regions. Notably, compounds 13 and 15 are specific to the EOs of the leaves and stems, respectively, of Saudi $O$. vulgare L., whereas compounds 9 and 8 were only found in the leaves and stems, respectively, of Jordanian $O$. vulgare L. The identified compounds and their relative contents are listed in Table 1 according to their elution order on a nonpolar HP-5MS column.
The phytochemical constituents of the stems and leaves of both Saudi and Jordanian O. vulgare L. samples are dominated by oxygenated monoterpenes. Among the studied EOs, the stem and leaf oils of the Saudi plant contain the largest amount of monoterpenes, i.e., $88.5 \%$ and $78.9 \%$, respectively, whereas its Jordanian counterpart contains $75.4 \%$ and $62.7 \%$, respectively. The next major chemical class is the monoterpene hydrocarbons, which are present in large amount in the leaf oils of both Saudi (17.2\%) and Jordanian (30.9\%) plants, where their stem oils contain $5.0 \%$ and $2.4 \%$, respectively. The other constituents, which were found in relatively smaller amounts in all studied EOs, are sesquiterpene hydrocarbons, oxygenated sesquiterpenes, aliphatic hydrocarbons, oxygenated aliphatic hydrocarbons, aromatics, and diterpenes (Fig. 3). Totally, 69 monoterpenoids were identified in the studied EOs. The oxygenated monoterpenes are mainly comprised of thymol, carvacrol, trans-sabinene hydrate, and terpinen-4-ol. Among the squiterpenoids, only $\beta$-caryophyllene was found in considerable quantity, whereas the other sesquiterpenoids such as germacrene D, germacrene D-4-ol, spathulenol, and caryophyllene oxide were present in minute concentrations (cf. Table 1).

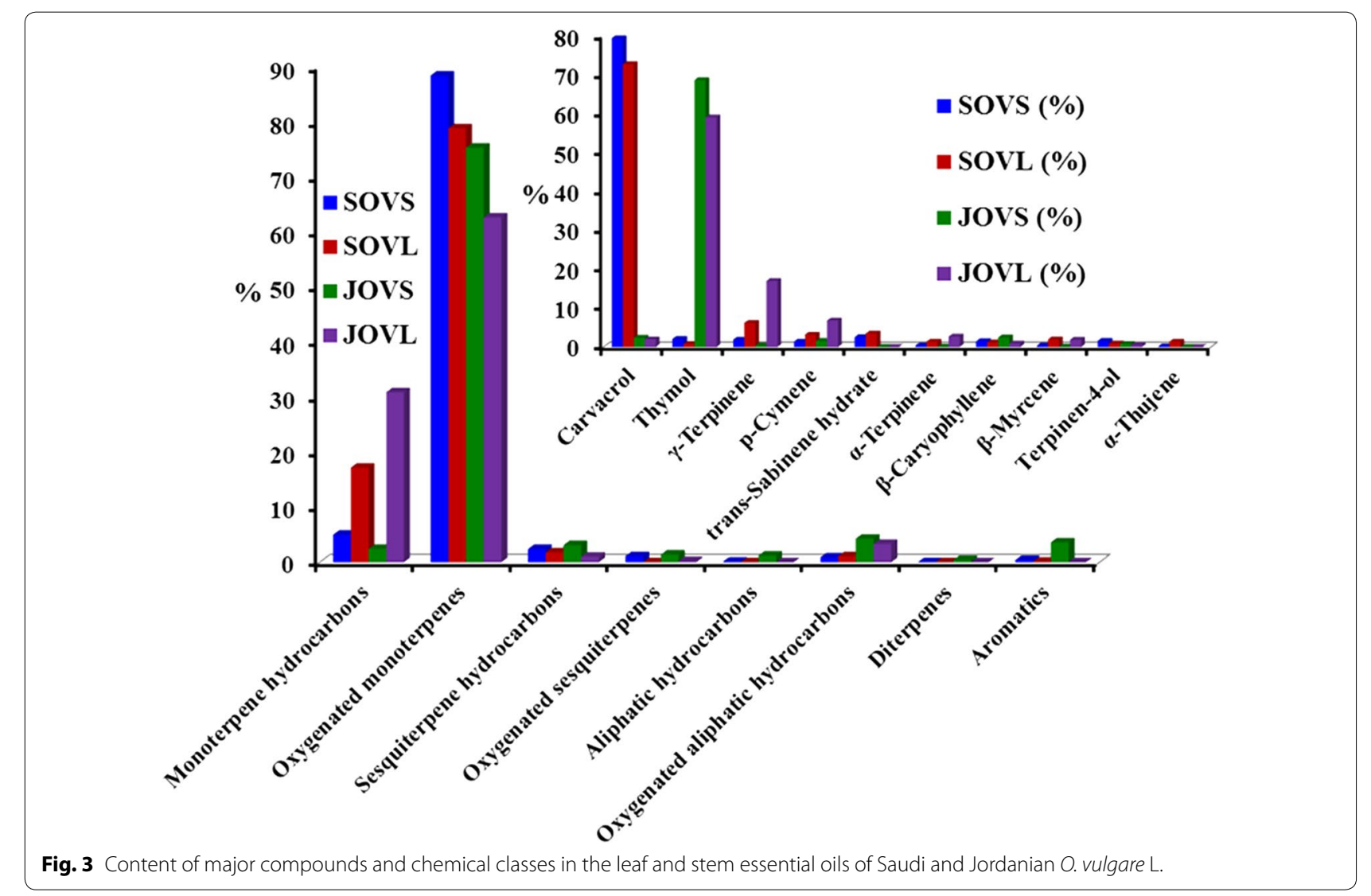




\section{Antimicrobial activity}

All the tested samples exhibited significant antimicrobial activity against both Gram-positive and Gram-negative bacteria. The growth inhibition of $E$. coli (a commonly used Gram-negative bacteria), which was measured in terms of the change in OD600 with various concentrations of the test compounds, is shown in Fig. 4a.

Clearly, Saudi O. vulgaris leaf EO (SOVL) was the least inhibitory, and the complete inhibition of E. coli growth was observed only at a concentration of $300 \mu \mathrm{g} / \mathrm{mL}$. Thymol exhibited the highest antimicrobial activity, inhibiting the growth of $E$. coli completely at a concentration of $100 \mu \mathrm{g} / \mathrm{mL}$ (Fig. 4). The antimicrobial activities of carvacrol and Saudi O. vulgare L. stem EO (SOVS) were comparable to those of thymol but varied in their half maximal inhibitory concentration $\left(\mathrm{IC}_{50}\right)$ values, as listed in Table 2. In contrast, Jordanian O. vulgare L. leaf and stem EOs (JOVL and JOVS, respectively) inhibited the growth of $E$. coli completely at a concentration of $200 \mu \mathrm{g} /$ $\mathrm{mL}$.
The antimicrobial activity of the samples against another Gram-negative bacterium, P. aeruginosa, is shown in Fig. 4b. Because P. aeruginosa grows more vigorously than $E$. coli, inhibition was observed at a comparatively higher concentration. As observed for E. coli, the most effective compound against $P$. aeruginosa was also thymol, inhibiting growth completely at a concentration of $100 \mu \mathrm{g} / \mathrm{mL}$. In contrast, carvacrol inhibited growth at $300 \mu \mathrm{g} / \mathrm{mL}$. The SOVL could not inhibit the growth completely, even at the highest test concentration, $500 \mu \mathrm{g} /$ $\mathrm{mL}$. The minimum inhibitory concentration (MIC) values of the tested samples against $P$. aeruginosa are listed in Table 2. Based on these values, the compounds can be arranged in order according to their microbicidal activity against $P$. aeruginosa (Table 3).

All the tested samples also exhibited good antimicrobial activity against the two tested Gram-positive bacteria. The antimicrobial activity of the tested samples against M. luteus is shown in Fig. 5. The figure clearly shows that SOVL was the least effective in inhibiting the
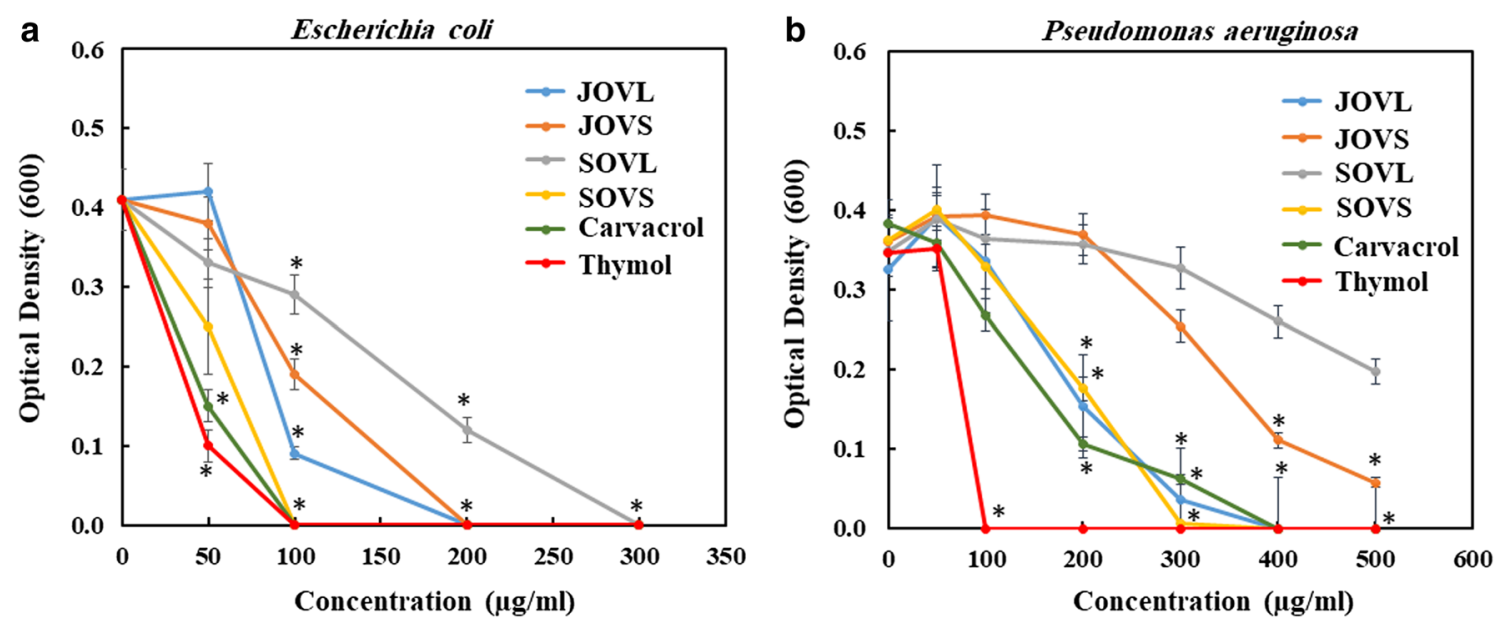

Fig. 4 Change in $\mathrm{OD}_{600}$ of Gram-negative bacteria (E. coli (a) and P. aeruginosa (b) following treatment with different samples. Asterisk indicates the values that are significantly different from the control ( $p$ value $<0.005)$

Table 2 The $\mathrm{IC}_{50}$ values obtained with different samples against Gram-negative and Gram-positive bacteria

\begin{tabular}{|c|c|c|c|c|c|c|c|c|}
\hline \multirow[t]{2}{*}{ Organism } & \multicolumn{8}{|c|}{$\mathrm{IC}_{50}(\mu \mathrm{g} / \mathrm{mL})$} \\
\hline & $\overline{\text { JOVL }}$ & Jovs & SOVL & sovs & Carvacrol & Thymol & $A m p^{a}$ & $\mathrm{Km}^{\mathrm{a}}$ \\
\hline \multicolumn{9}{|l|}{ Gram-negative } \\
\hline E. coli & 99 & 107 & 150 & 55 & 54 & 43 & 40 & 10 \\
\hline$P$. aeruginosa & 190 & 325 & 430 & 196 & 151 & 63 & 20 & 40 \\
\hline \multicolumn{9}{|l|}{ Gram-positive } \\
\hline M. luteus & 84 & 77 & 800 & 67 & 66 & 27 & 20 & 40 \\
\hline S. aureus & 77 & 83 & 380 & 63 & 53 & 41 & 250 & 15 \\
\hline
\end{tabular}

a MIC values obatined in this study 
Table 3 Antimicrobial activity of essential oils and their purified compounds

\begin{tabular}{|c|c|c|}
\hline Bacteria type & Organisms & Activity \\
\hline \multirow[t]{2}{*}{ Gram-negative } & E. coli & $\begin{array}{l}\text { Thymol }>\text { carvacrol }>\text { SOVS }>J O V L>J O V \\
\text { S }>\text { SOVL }\end{array}$ \\
\hline & P. aeruginosa & $\begin{array}{l}\text { Thymol }>\text { carvacrol }>\mathrm{JOVL}>\mathrm{SOVS}>\mathrm{JOV} \\
\mathrm{S}>\mathrm{SOVL}\end{array}$ \\
\hline \multirow[t]{2}{*}{ Gram-positive } & M. luteus & $\begin{array}{l}\text { Thymol }>\text { carvacrol }>\mathrm{JOVL}>\mathrm{SOVS}>\mathrm{JOV} \\
\mathrm{L}>\mathrm{SOVL}\end{array}$ \\
\hline & S. aureus & $\begin{array}{l}\text { Thymol }>\text { carvacrol }>\text { SOVS }>J O V L>J O V \\
\text { S }>\text { SOVL }\end{array}$ \\
\hline
\end{tabular}

growth of $M$. luteus, and complete growth inhibition was not observed even at the highest test concentration of $500 \mu \mathrm{g} / \mathrm{mL}$. However, thymol most effectively inhibited the growth of $M$. luteus, showing significant growth inhibition at $50 \mu \mathrm{g} / \mathrm{mL}$ (Fig. $5 \mathrm{a}$ ). In contrast, carvacrol was able to completely inhibit the growth of $M$. luteus only at $100 \mu \mathrm{g} / \mathrm{mL}$. Based on the $\mathrm{IC}_{50}$ values, the antimicrobial activity against $M$. luteus can be arranged in the order given in Table 3.

A similar trend in the antimicrobial activity of the samples was observed against another Gram-positive bacteria, $S$. aureus (Fig. 5b). In this test, thymol most effectively inhibited the growth of $S$. aureus, and SOVL was the least effective against $S$. aureus. Hence, the test compounds can be arranged in the order given in Table 3 based on their $\mathrm{IC}_{50}$ values against $S$. aureus.

The trend in antimicrobial activity was very similar in all the four tested bacteria. However, it is evident from the MIC values listed in Table 2 that the tested compounds exhibited higher antimicrobial activity against the tested Gram-positive bacteria than against the
Gram-negative bacteria. This trend is also in agreement with most of the studies investigating the action of whole EOs against food spoilage organisms and foodborne pathogens, which suggest that the EOs are slightly more active against Gram-positive than Gram-negative bacteria (Burt 2004). However, in several studies, the reverse trend has been observed (Pesavento et al. 2015). Typically, Gram-negative bacteria have an outer membrane surrounding the cell wall, which makes them susceptible to the action of common antibacterial agents (Vaara 1992). Notably, the MIC values of the samples tested in this study were many times lower than the MIC values of kanamycin and ampicillin obtained in this study (Table 2).

\section{Discussion}

Typically, the essential oils of plants of the same species grown in different locations exhibit significant variations in composition because of the different environmental conditions, such as altitude, solar exposure, and soil composition (Figueiredo et al. 2008). These geographic variations of the yield and composition of volatile oils have been found in several species, demonstrating that distinct chemotypes of plants grow in different locations (Bhatt et al. 2019; Fikry et al. 2019; Hussain et al. 2008; Tanasescu et al. 2019). Therefore, the study of the chemical variability and yield of volatile oils of commercially important plants such as $O$. vulgare L. grown in different locations is highly desirable. In this study, we made a detailed analysis of the chemical constituents of the leaf and stem volatile oils of $O$. vulgare L. grown in two different geographical locations: Saudi Arabia and Jordan. This study is the first example of the characterization of the essential oil constituents of the leaf and stem volatile
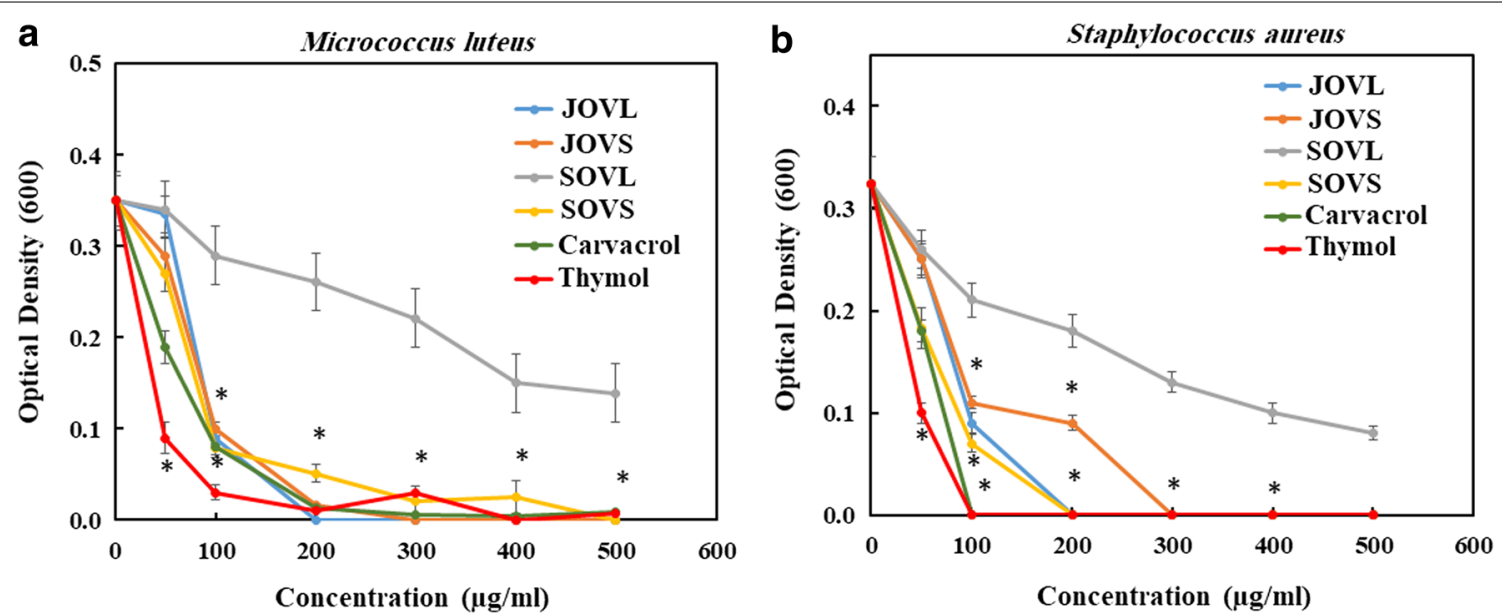

Fig. 5 Growth inhibition of Gram-positive bacteria (M. luteus (a) and S. aureus (b)), as measured by the change in $\mathrm{OD}_{600}$ following treatment with different samples. Asterisk indicates the values that are significantly different from the control ( $p$ value $<0.005$ ) 
oils of $O$. vulgare L. from these regions, and the components are compared with the EOs of $O$. vulgare L. grown in other parts of the world.

Based on the monoterpene constituents, both Saudi and Jordanian plants are classified as cymyl chemotypes, which is typical of various Origanum species grown in the Mediterranean (Lukas et al. 2015). For instance, the Origanum populations of southern and coastal Europe including Portugal, Spain, and Greece are often dominated by the cymyl chemotype. The Origanum species from the Middle East have been rarely studied, but the results obtained from the essential oils of Saudi and Jordanian $O$. vulgare $\mathrm{L}$. indicate that the cymyl chemotype should predominate in most Origanum species from these regions. Althogh studied oils are classified as cymyl chemotypes, however, significant quantitative differences between four different oils are clearly apparent in two major isomeric phenols, i.e., carvacrol and thymol, and their biosynthetic precursors, i.e., $\gamma$-terpinene and $p$-cymene (Sivropoulou et al. 1996). For instance, the stem and leaf oils of Saudi Origanum contain carvacrol as the major component, containing $79.5 \%$ and $71.9 \%$, respectively, followed by $\gamma$-terpinene (stem oil $1.9 \%$ and leaf oil $6.2 \%$ ) and $p$-cymene (stem oil $1.4 \%$ and leaf oil $3.2 \%)$; thus, it is characterized as a carvacrol chemotype. In contrast, the studied oils of Jordanian Origanum contain thymol as the major component, containing $68.7 \%$ in the stem oil and $59.1 \%$ in the leaf oil, while its biosynthetic precursors $\gamma$-terpinene (stem oil $0.4 \%$ and leaf oil $17.0 \%$ ) and $p$-cymene (stem oil $1.6 \%$ and leaf oil $6.8 \%$ ) were also present in significant amounts; therefore, it is characterized as a thymol chemotype (Fig. 3 ). This variation in the phytochemical constituents of the stem and leaf oils of both Jordanian and Saudi O. vulgare L. can be attributed to the differences in the climatic conditions, geographical location of collection sites, and other genetic factors, as has been observed in several other species of Origanum from different regions (Sarikurkcu et al. 2015; Vokou et al. 1993).

Typically, the formation of thymol and carvacrol involves the hydroxylation of $\gamma$-terpinene and $p$-cymene precursors (Poulose and Croteau 1978). This process involves cytochrome P450 monooxygenases for the conversion of $\gamma$-terpinene to thymol and carvacrol via eleven cytochrome P450 gene sequences (CYP71D178CYP71D182) from oregano, thyme, and marjoram (Crocoll et al. 2010). Thus, it has been suggested that CYP71D179/182 is responsible for the biosynthesis of thymol, whereas CYP71D181 may be involved in carvacrol biosynthesis. Therefore, in this study, the presence of a large amount of thymol in Jordanian Origanum can be attributed to the aforementioned biosynthetic process, in which CYP71D179/182 transcription of P450 is more active compared to the transcription of other genes. In contrast, CYP71D181 transcription might play a more active role in the biosynthesis of carvacrol in Saudi Origanum. Therefore, apart from the climatic and geographic conditions, other enzymatic processes may also be responsible for the variation in the phytochemical constituents of both Saudi and Jordanian Origanum plants.

The phytoconstituents of the studied EOs were further identified by advanced characterization techniques, including ${ }^{1} \mathrm{H}$ and ${ }^{13} \mathrm{C}$ NMR (cf. Additional file 1: Fig. S3a, b). In these constituents, thymol (2-isopropyl5-methylphenol), and its isomer carvacrol (2-methyl5-(1-methylethyl)-phenol) were identified as the major components of Jordanian and Saudi Origanum respectively. These isomeric phytomolecules have widespread applications in various fields including pharmaceutical, food and cosmetic industries (Javed et al. 2013; Sobczak et al. 2014; Venturini et al. 2002; Andersen 2006; Suntres et al. 2015).

In this study, we found that Jordanian Origanum is an important source of thymol, whereas carvacrol can be obtained on a large scale from Saudi Origanum. Apart from thymol and carvacrol (Additional file 1: Fig. S4), some of the other phytochemical components such as, $\alpha$-thujene, $\beta$-myrcene, $\alpha$-terpinene, $m$-cymene, $\quad p$-cymene, $\gamma$-terpinene, trans-sabinene hydrate, terpinen-4-ol, $\beta$-caryophyllene, 3,3,4,5,5,8-hexamethyl-2,6-dihydro-s-indacene-1,7-dione, and 2-tert-butyl-4-(dimethylbenzyl)phenol were found in noteworthy amounts in the studied oils. The stem and leaf EOs of Jordanian Origanum show several qualitative similarities, which is clearly reflected by the presence of 28 components in both samples in considerable amounts, although their relative quantities are different, i.e., $\beta$-myrcene ( $0.1 \%$ and $1.9 \%), \alpha$-terpinene $(0.1 \%$ and $2.7 \%)$, $p$-cymene (1.6\% and $6.8 \%), \gamma$-terpinene $(0.4 \%$ and $17.0 \%)$, terpinen-4-ol ( $0.8 \%$ and $0.5 \%)$, and $\beta$-caryophyllene $(2.5 \%$ and $0.9 \%$ ), respectively. In addition, certain components could be found in only one of the oils; for example, 3,3,4,5,5,8-hexamethyl-2,6-dihydro-s-indacene-1,7-dione (1.5\%) and 2-tert-butyl-4-(dimethylbenzyl)phenol (2.1\%) (Additional file 1: Fig. S4) were only present in the stem oil of Jordanian Origanum. Notably, the leaf oil of Jordanian Origanum proved to be an excellent source of $\gamma$-terpinene, which is present in large amounts (17.0\%) in the sample. Although the Saudi Origanum contain similar phytochemical constituents in different quantities, as shown in Table 1, certain components are specific to this particular species. For instance, trans-sabinene hydrate, 2-heptanol, $\alpha$-thujene, $\alpha$-campholenal, cis-p-mentha2,8-dien-1-ol, isoborneol, umbellulone, $m$-cymen-8-ol, myrtenal, cis-piperitol, $n$-decanal, methyl carvacrol, and 
carvacrol acetate are present in minute concentrations or in trace amounts.

A correlation between the antimicrobial activity of the tested compounds and the compositions of the stem and leaf oils of both Saudi and Jordanian origin used in this study was made. On comparing the activities of these compounds against the four organisms studied, it was found that thymol has showed the highest activity against all the tested organisms, followed by that of carvacrol. Both thymol and carvacrol are structurally very similar, having the hydroxyl group at a different location on the phenol ring. Typically, they appear to act by making the cell membrane permeable. In the case of Gram-negative bacteria, thymol and carvacrol induce the disintegration of the outer membrane, releasing lipopolysaccharides (LPS) and increasing the permeability of the cytoplasmic membrane to adenosine triphosphate (ATP) (Burt 2004). Furthermore, it has been proposed that these compounds can interact with membrane proteins and enzymes, as well as intracellular targets (Engel et al. 2017). In most cases, both thymol and carvacrol exhibit comparable antimicrobial properties because of their similar structures. However, in some cases, thymol has demonstrated better activity compared to carvacrol under similar conditions.

Studies of the antibacterial activity of thymol and carvacrol isolated from the EO of O. dictamnus L. have revealed that thymol exhibits stronger activity than carvacrol against most microbial types (Liolios et al. 2009). Similarly, in our previous study on S. mutans (a wellknown oral pathogen), we observed that thymol showed a relatively higher activity than carvacrol. Thymol showed higher activity by effectively inhibiting the growth of the tested organism by inducing stress and autolysis (Khan et al. 2017). Thymol also significantly disrupts the biofilms formed by S. mutans. As far as SOVL, SOVS, JOVL, and JOVS are concerned, JOVL and SOVS exhibited the highest antimicrobial activities against all the four tested organisms. Furthermore, the antimicrobial activities of these two essential oils were comparable. As shown in Table 1, JOVL contains $59.1 \%$ thymol and $2.0 \%$ carvacrol, while SOVS contains about $79.5 \%$ carvacrol and $2.1 \%$ thymol. Therefore, SOVS has the highest amount of the pure compound probably responsible for the remarkable antimicrobial activity. The cumulative effect of carvacrol and thymol has not yet been examined. JOVL shows significant activity, probably because of the cumulative effect of thymol with some other constituents including carvacrol and $\gamma$-terpinene. Notably, JOVL consists of the highest amount of $\gamma$-terpinene, constituting $17.0 \%$ of the total. $\gamma$-Terpinene is already known to have significant antimicrobial activity against a number of pathogenic microorganisms, even at a concentration of $0.1 \%(\mathrm{v} / \mathrm{v})$
(Delaquis et al. 2002). JOVL also contains 7.0\% cymene (alkyl benzene), which has also been shown to have good antimicrobial activity (Delaquis et al. 2002). Thus, it is very highly likely that the cumulative effect of thymol, carvacrol, $p$-cymene, and $\gamma$-terpinene resulted in the remarkable antimicrobial activity that was observed in this study.

The next most active essential oil was JOVS, which contains $68.7 \%$ thymol and $2.4 \%$ carvacrol. Other constituents that were present in significant amount in this essential oil were $\beta$-caryophyllene (2.5\%), 2-tert-butyl4-(dimethylbenzyl) phenol (2.1\%), and $p$-cymene $(1.6 \%)$. The cumulative effect of all these compounds may be responsible for the antimicrobial activity. The least activity was observed for SOVL, which mainly contain carvacrol $(72.8 \%), \gamma$-terpinene $(6.2 \%)$, trans-sabinene hydrate (3.5\%), $p$-cymene $(3.2 \%)$, and $\beta$-myrcene $(2.0 \%)$. These results reveal that the whole EOs and individual components of the oils studied, including thymol and carvacrol, show different degrees of activity against Gram-positive and Gram-negative bacteria. This is in agreement with the trend that the chemical composition of the EOs from a particular plant species vary with geographical origin and harvesting period. However, we can only speculate about the effects of the constituents and their combinations on the antimicrobial activity, and future detailed investigations on antibiofilm activity and antiquoroum sensing activities are required. Based on our results, we propose that plant species from different regions produce different compounds or mixtures of the compounds, and these variations result in completely different bioactivities.

\section{Supplementary information}

Supplementary information accompanies this paper at https://doi. org/10.1186/s13568-019-0893-3.

Additional file 1. Additional figures and tables.

\begin{abstract}
Acknowledgements
The authors extend their appreciation to the Deanship of Scientific Research and RSSU at King Saud University for their technical support and funding this work through the research group Project No. RG-1438-077.
\end{abstract}

\section{Authors' contributions}

MK, main author designed and executed the study. STK, he studied the biological activities of the samples. MK, he helped in preparing manuscript. $\mathrm{AAM}$, he collected the plant materials. AM, helped in experimental work, HZA, arranged funding and helped in preparing the manuscript. All authors read and approved the final manuscript.

Funding

Not applicable.

Availability of data and materials

The [GC-MS/GC-FID, NMR] data used to support the findings of this study are included within the article and additional file(s). 


\section{Ethics approval and consent to participate}

This article does not contain any studies with human participants or animals performed by any of the authors.

\section{Consent for publication}

Not applicable being an open access publication.

\section{Competing interests}

The authors declare that they have no competing interests.

\section{Author details}

${ }^{1}$ Department of Chemistry, College of Science, King Saud University, P.O. Box 2455, Riyadh 11451, Saudi Arabia. ${ }^{2}$ Department of Agricultural Microbiology, Aligarh Muslim University, Aligarh 202002, U.P, India.

Received: 11 April 2019 Accepted: 4 October 2019 Published online: 31 October 2019

\section{References}

Adams R (2007) Identification of essential oil components by gas chromatography/mass spectrometry. Identification of essential oil components by gas chromatography/mass spectrometry(Ed. 4)

Ait-Ouazzou A, Cherrat L, Espina L, Lorán S, Rota C, Pagán R (2011) The antimicrobial activity of hydrophobic essential oil constituents acting alone or in combined processes of food preservation. Innov Food Sci Emerg Technol 12(3):320-329

Aligiannis N, Kalpoutzakis E, Mitaku S, Chinou IB (2001) Composition and antimicrobial activity of the essential oils of two Origanum species. J Agric Food Chem 49(9):4168-4170

Andersen A (2006) Final report on the safety assessment of sodium p-chlorom-cresol, p-chloro-m-cresol, chlorothymol, mixed cresols, m-cresol, o-cresol, p-cresol, isopropyl cresols, thymol, o-cymen-5-ol, and carvacrol. Int J Toxicol 25:29-127

Atanasov AG, Waltenberger B, Pferschy-Wenzig E-M, Linder T, Wawrosch C, Uhrin P, TemmI V, Wang L, Schwaiger S, Heiss EH (2015) Discovery and resupply of pharmacologically active plant-derived natural products: a review. Biotechnol Adv 33(8):1582-1614

Bakkali F, Averbeck S, Averbeck D, Idaomar M (2008) Biological effects of essential oils-a review. Food Chem Toxicol 46(2):446-475

Bassolé IHN, Juliani HR (2012) Essential oils in combination and their antimicrobial properties. Molecules 17(4):3989-4006

Bhatt S, Tewari G, Pande C, Prakash O, Tripathi S (2019) Aroma Profile and Antioxidant Potential of Origanum vulgare L.: Impact of Drying. J Essent Oil-Bear Plants 22(1):214-230

Burt S (2004) Essential oils: their antibacterial properties and potential applications in foods - a review. Int J Food Microbiol 94(3):223-253

Carvalho IT, Estevinho BN, Santos L (2016) Application of microencapsulated essential oils in cosmetic and personal healthcare products-a review. Int J Cosmetic Sci 38(2):109-119

Crocoll C, Asbach J, Novak J, Gershenzon J, Degenhardt J (2010) Terpene synthases of oregano (Origanum vulgare L.) and their roles in the pathway and regulation of terpene biosynthesis. Plant Mol Biol 73(6):587-603

de Barros JC, da Conceição ML, Neto NJG, da Costa ACV, Júnior JPS, Junior IDB, de Souza EL (2009) Interference of Origanum vulgare L. essential oil on the growth and some physiological characteristics of Staphylococcus aureus strains isolated from foods. LWT-Food Sci Technol 42(6):1139-1143

De Martino L, De Feo V, Nazzaro F (2009) Chemical composition and in vitro antimicrobial and mutagenic activities of seven Lamiaceae essential oils. Molecules 14(10):4213-4230

Delaquis PJ, Stanich K, Girard B, Mazza G (2002) Antimicrobial activity of individual and mixed fractions of dill, cilantro, coriander and eucalyptus essential oils. Int J Food Microbiol 74(1-2):101-109

Engel JB, Heckler C, Tondo EC, Daroit DJ, da Silva Malheiros P (2017) Antimicrobial activity of free and liposome-encapsulated thymol and carvacrol against Salmonella and Staphylococcus aureus adhered to stainless steel. Int J Food Microbiol 252:18-23

Figueiredo AC, Barroso JG, Pedro LG, Scheffer JJ (2008) Factors affecting secondary metabolite production in plants: volatile components and essential oils. Flavour Fragrance J 23(4):213-226
Fikry S, Khalil N, Salama O (2019) Chemical profiling, biostatic and biocidal dynamics of Origanum vulgare L essential oil. AMB Expr 9(1):41

Gutierrez J, Barry-Ryan C, Bourke P (2008) The antimicrobial efficacy of plant essential oil combinations and interactions with food ingredients. Int J Food Microbiol 124(1):91-97

Hussain Al, Anwar F, Sherazi STH, Przybylski R (2008) Chemical composition, antioxidant and antimicrobial activities of basil (Ocimum basilicum) essential oils depends on seasonal variations. Food Chem 108(3):986-995

Ibadullayeva S, Shahmuradova M, Gahramanova M, Aliyeva SG (2012) Use of Wild Plants at Dermatosis (Skin Deseases): Ethnobotany

Janssen A, Scheffer J, Svendsen AB (1987) Antimicrobial activity of essential oils: a 1976-1986 literature review. Aspects of the test methods. Planta Med 53(05):395-398

Javed H, Erum S, Tabassum S, Ameen F (2013) An overview on medicinal importance of Thymus vulgaris. J Asian Sci Res 3(10):974

Khan M, Al-Saleem MS, Alkhathlan HZ (2016) A detailed study on chemical characterization of essential oil components of two Plectranthus species grown in Saudi Arabia. J Saudi Chem Soc 20(6):711-721

Khan ST, Khan M, Ahmad J, Wahab R, Abd-Elkader OH, Musarrat J, Alkhathlan HZ, Al-Kedhairy AA (2017) Thymol and carvacrol induce autolysis, stress, growth inhibition and reduce the biofilm formation by Streptococcus mutans. AMB Expr 7(1):49

Khan M, Khan ST, Khan NA, Mahmood A, Al-Kedhairy AA, Alkhathlan HZ (2018) The composition of the essential oil and aqueous distillate of Origanum vulgare L. growing in Saudi Arabia and evaluation of their antibacterial activity. Arab J Chem 11(8):1189-1200

Kokkini S, Karousou R, Vokou D (1994) Pattern of geographic variations of Origanum vulgare trichomes and essential oil content in Greece. Biochem Syst Ecol 22(5):517-528

Liolios C, Gortzi O, Lalas S, Tsaknis J, Chinou I (2009) Liposomal incorporation of carvacrol and thymol isolated from the essential oil of Origanum dictamnus $L$. and in vitro antimicrobial activity. Food Chem 112(1):77-83

Lukas B, Schmiderer C, Novak J (2015) Essential oil diversity of European Origanum vulgare L. (Lamiaceae). Phytochemistry 119:32-40

Maggio A, Rosselli S, Bruno M (2016) Essential oils and pure volatile compounds as potential drugs in Alzheimer's disease therapy: an updated review of the literature. Curr Pharm Des 22(26):4011-4027

Pesavento G, Calonico C, Bilia A, Barnabei M, Calesini F, Addona R, Mencarelli L, Carmagnini L, Di Martino M, Nostro AL (2015) Antibacterial activity of Oregano, Rosmarinus and Thymus essential oils against Staphylococcus aureus and Listeria monocytogenes in beef meatballs. Food Control 54:188-199

Pichersky E, Noel JP, Dudareva N (2006) Biosynthesis of plant volatiles: nature's diversity and ingenuity. Science 311(5762):808-811

Poulose A, Croteau R (1978) Biosynthesis of aromatic monoterpenes: conversion of $\gamma$-terpinene to $\mathrm{p}$-cymene and thymol in Thymus vulgaris $\mathrm{L}$. Arch Biochem Biophys 187(2):307-314

Raut JS, Karuppayil SM (2014) A status review on the medicinal properties of essential oils. Ind Crops Prod 62:250-264

Sacchetti G, Maietti S, Muzzoli M, Scaglianti M, Manfredini S, Radice M, Bruni R (2005) Comparative evaluation of 11 essential oils of different origin as functional antioxidants, antiradicals and antimicrobials in foods. Food Chem 91(4):621-632

Sarikurkcu C, Zengin G, Oskay M, Uysal S, Ceylan R, Aktumsek A (2015) Composition, antioxidant, antimicrobial and enzyme inhibition activities of two Origanum vulgare subspecies (subsp. vulgare and subsp. hirtum) essential oils. Ind Crops Prod 70:178-184

Sivropoulou A, Papanikolaou E, Nikolaou C, Kokkini S, Lanaras T, Arsenakis M (1996) Antimicrobial and cytotoxic activities of Origanum essential oils. J Agric Food Chem 44(5):1202-1205

Sobczak M, Kalemba D, Ferenc B, Zylinska L (2014) Limited protective properties of thymol and thyme oil on differentiated PC12 cells with downregulated Mgst1. J Appl Biomed 12(4):235-243

Soković MD, Vukojević J, Marin PD, Brkić DD, Vajs V, Van Griensven LJ (2009) Chemical composition of essential oilsof thymus and mentha species and their antifungal activities. Molecules 14(1):238-249

Suntres ZE, Coccimiglio J, Alipour M (2015) The bioactivity and toxicological actions of carvacrol. Crit Rev Food Sci Nutr 55(3):304-318

Tanasescu S, Nitu R, Dahma G, Pilut C, Diaconu M, Neagoe O, Muntean D, Horhat ID, Dragomir A, Lighezan D (2019) Chemical composition and 
antimicrobial activity of essential oil of Romanian Origanum vulgare. Rev Chim 70(5):1744-1745

Vaara M (1992) Agents that increase the permeability of the outer membrane. Microbiol Rev 56(3):395-411

Valnet J, Duraffourd C, Lapraz J (1978) The aromagram: new results and an attempt at interpretation of 68 clinical cases. Plant Med Phytother 12(1):43-52

Veiga A, Maria da Graça TT, Rossa LS, Mengarda M, Stofella NC, Oliveira LJ, Gonçalves AG, Murakami FS (2019) Colorimetric microdilution assay: validation of a standard method for determination of MIC, IC50\%, and IC $90 \%$ of antimicrobial compounds. J Microbiol Methods 162:50-61

Venturini M, Blanco D, Oria R (2002) In vitro antifungal activity of several antimicrobial compounds against Penicillium expansum. J Food Prot 65(5):834-839
Vlase L, Benedec D, Hanganu D, Damian G, Csillag I, Sevastre B, Mot AC, SilaghiDumitrescu R, Tilea I (2014) Evaluation of antioxidant and antimicrobial activities and phenolic profile for Hyssopus officinalis, Ocimum basilicum and Teucrium chamaedrys. Molecules 19(5):5490-5507

Vokou D, Kokkini S, Bessiere J-M (1993) Geographic variation of Greek oregano (Origanum vulgare ssp. hirtum) essential oils. Biochem Syst Ecol 21(2):287-295

\section{Publisher's Note}

Springer Nature remains neutral with regard to jurisdictional claims in published maps and institutional affiliations.

\section{Submit your manuscript to a SpringerOpen ${ }^{\circ}$ journal and benefit from:}

- Convenient online submission

- Rigorous peer review

- Open access: articles freely available online

- High visibility within the field

- Retaining the copyright to your article

Submit your next manuscript at $\boldsymbol{\nabla}$ springeropen.com 